\title{
scripted
}

Volume 10, Issue 2, August 2013

\section{EDITORIAL: COPYRIGHT MANAGEMENT FOR OPEN Collaborative Projects -INbound Licensing Models FOR OPEN INNOVATION}

\author{
Catharina Maracke*
}

\begin{abstract}
Introduction to the special section on open collaborative projects.
\end{abstract}

DOI: $10.2966 /$ scrip.100213.140

\section{cc) $(1) \odot$ \\ EY No ND (C) Catharina Maracke 2013. This work is licensed under a Creative Commons Licence. Please click on the link to read the terms and conditions.}

\footnotetext{
* Dr. iur., Associate Professor, Graduate School of Media and Governance, Shonan Fujisawa Campus, Keio University.
} 
Public licensing such as Creative Commons, the Free Art License or the GNU General Public License ${ }^{1}$ has emerged rapidly over the past several years as an important and innovative step towards reducing the transaction costs imposed by the current copyright dilemma. ${ }^{2}$ In a digital world of legal uncertainties, these "easy-touse" standardized copyright agreements offer developers, creators and other licensors a simple way to say what freedoms they want their content to carry.

Much less work has been done on the legal questions about how contributions may be combined in the first place. While open source and open content projects have been able to cooperate through technical standards, the same projects still tailor various legal agreements relating to the copyright and patent permissions of contributions to each project. The result is a complexity of different legal terms to be reviewed and negotiated, which not only increases transaction costs and risks, but constitutes a weakness and potential friction in the growth of collaborative efforts vital for all forms of open innovation.

One potential way to effectivley structure rights between developers (authors), the projects (entities) that distribute their works, and the users (end licensees) of their work is the use of contributor agreements. ${ }^{3}$ Contributor agreements, to describe them briefly, define and clarify the terms, under which a contribution (code, translation, artwork, etc.) is made to an open source or open content project. Thus, using a contributor agreement can provide confidence in the origin and ownership of individual contributions and thereby protect the project and its organisers, the users of the software and also the contributors. ${ }^{4}$ While contributor agreements are increasingly being adopted by open source projects ${ }^{5}$, the benefits and downsides have been the

\footnotetext{
${ }^{1}$ http://creativecommons.org/, http://artlibre.org/licence/lal/en, http://www.gnu.org/licenses/gpl.html

${ }^{2}$ Most creations being accessed through the Internet are subject to copyright. And because of how digital technologies are functioning most uses necessarily make a temporary/permanent copy or require distribution, which can in turn cause friction under the default terms of copyright. For an overview on copyright and digital technologies see U Gasser and S Ernst, From Shakespeare to DJ Danger Mouse: A Quick Look at Copyright and User Creativity in the Digital Age, Berkman Center for Internet \& Society Research Publication, June 2006, available at http://papers.ssrn.com/sol3/papers.cfm?abstract_id=909223; T Kreutzer, Das Modell des Deutschen Urheberrechts und Regelungsalternativen, 2008; L Lessig: Laws that choke creativity, TED Talk filmed $\quad$ March 2007 available at http://www.ted.com/talks/larry_lessig_says the law_is_strangling_creativity.html
}

${ }^{3}$ Contributor agreements are only one possible tool out of many in an overall legal strategy for free and open source and other open collaborative projects. Many projects have chosen to implement contributor agreements, such as the Free Software Foundation, which requests assignment of copyright (http://www.gnu.org/licenses/why-assign.html) or the Apache Foundation (http://www.apache.org/licenses/icla.txt), whereas many other projects have chosen not to use contributor agreements, see the Linux Developer Certificate of Origin available at (http://elinux.org/Developer_Certificate_Of_Origin.

${ }^{4}$ For details see M Michlmayr, Open Source Contributor Agreements: Purpose and Scope, FOSS BAZAAR 2010 available at https://fossbazaar.org/content/open-source-contributor-agreementspurpose-and-scope/

${ }^{5}$ See the following examples to name only a few:

KDE's Fiduciary License Agreements available at http://ev.kde.org/rules/fla.php 
subject of intense and at times emotional discussion. Arguments about the appropriate form for contributor agreements intensified when project Harmony was launched in 2011 as the first attempt at standardized templates for contributor agreements. ${ }^{6}$ In addition to the debate around substance and exact wording of the agreements, there were also critics who claimed that harmonized contributor agreements were a means for companies to establish the transfer of rights from contributors to commercial investors as an industry standard. ${ }^{7}$

The subject and purpose of this special section is to deepen the discussion around the practices and legal pitfalls for contributor agreements. While discussion of contributor agreements has been largely confined to an Anglo-American legal context, free and open source software projects are increasingly global. The resulting inquiry is complex: What kind of framework is needed to enable a mechanism by which contributions from different sources can be appropriately combined in the first place? All four authors contributing to this section focus on selected legal questions and discuss different options to improve standardization efforts. The fact that this section looks into different legal questions for contributor agreements and suggests improvements for different drafting options is not intended to suggest that contributor agreements are necessary for all successful legal strategies. Rather, the aim is to reanimate the discussion, to provide additional generic information relevant for any legal strategy considered by open collaborative projects, and to broaden the perspective. Whereas most contributor agreements are associated with free and open source software projects, the underlying idea of collecting all necessary rights in the respective project can also be found in other areas, whenever it becomes important for the project to distribute a product and obtain the necessary rights to respond to legal disputes. Thus, the goal of this special section is to contribute to the overall discussion

Fedora: https://fedoraproject.org/wiki/Legal:Fedora_Project_Contributor_Agreement

Django https://www.djangoproject.com/foundation/cla/

Joomla! http://developer.joomla.org/cms/contribute.html

Zimbra: http://www.zimbra.com/license/contribution_agreement_2.0.html

Novell: ftp://sdk.provo.novell.com/ndk/evolution/docs/copyright_form.pdf

Mambo: http://mambo-manual.org/download/attachments/5833166/mca.pdf?version=1

SugarCRM: http://www.sugarforge.org/content/community/participate/contributor-agreement.php

Symbian: http://www.symlab.org/wiki/images/9/9e/Non-Member_Contribution_Agreement.pdf

Debian Social Contract: http://www.debian.org/social_contract

RedHat: http://www.redhat.com/licenses/ccmpl.html

Canonical: http://www.canonical.com/contributors

Google: http://code.google.com/legal/individual-cla-v1.0.html

Twitter: https://dev.twitter.com/opensource/cla

Ariba: http://aribaweb.org/AribaWeb_Contributor_Agreement.pdf

${ }^{6}$ The impetus was to create agreement templates with distinct but limited permutations. Each project can create its own contributor agreement from the templates, but because it is from a standardized set of possibilities it is easy to understand what choices the project has made, and how those differ from choices by others. See announcement available at http://www.ubuntu-user.com/Online/News/ProjectHarmony-Launches-Today, details of the agreements available at http://harmonyagreements.org and further information at http://lwn.net/Articles/450543/.

7 See the discussion and criticism following the launch of the Harmony agreements (http://harmonyagreements.org/) in 2011: B Kuhn, Project Harmony Considered Harmful, 2011 available at http://ebb.org/bkuhn/blog/2011/07/07/harmony-harmful.html and R Fontana, The Trouble With Harmony, 2011 available at http://opensource.com/law/11/7/trouble-harmony-part-1. 
of standardisation efforts for contributor agreements, whether they are related to software or other creations.

Discussing standardization efforts for contributor agreements has led to four critical legal issues: 1) The question of copyright assignments and legal consequences, 2) the question of internationalization, 3) the question of signature formalities, and 4) the exact scope of the patent license to be included in contributor agreements and especially the question of whether this patent license can be based on a defensive pledge. The last topic on patent law, which is controversially debated across different industries, will have to be elaborated upon with partners and pioneers in this field ${ }^{8}$ and be covered in a future article. Questions on copyright assignments and other drafting options, on internationalization, and on signature formalities are subject of this special section and invite comments and constructive input.

Hence, the first important aspect to be evaluated in the context of standardized contributor agreements is the differentiation between contributor license agreements and contributor assignment agreements: Assignment agreements require the assignment and therefore transfer of copyright in all contributions to the project owner, while license agreements grant an irrevocable license to allow the project owner to use the contribution. ${ }^{9}$ The main difference is that in the case of an assignment agreement, the copyright owner of the original contribution (contributor) transfers his entire copyright to the project owner, so that she becomes the owner of all rights recognized under the respective copyright law and can subsequently license these rights to any party, whereas in case of a copyright license agreement, the contributor remains the owner of such rights, but grants most of the exclusive statutory rights of copyright to the project owner.

These different drafting options for contributor agreements are not only important in the context of legal requirements and legal consequences as determined by different national copyright law. They are also of significant importance to the public perception of contributor agreements: Assignments can be perceived as the contributor giving up complete control over the contribution and as granting the project or company more rights than needed. This view of copyright assignments leads to the contradiction that while an assignment is often considered necessary to give the project owner all essential rights to legally enforce the license regime used by

\footnotetext{
8 See the "Defensive Patent License Project" and their licensing model available at https://docs.google.com/document/d/1eYp2YFQAcdjObCPx3Zak6Hntz XfEhmWFVyI0CTJGSQ/edit the Open Invention Network available at http://www.openinventionnetwork.com/patents.php, Twitter's "Innovators Patent Agreement" available at https://github.com/twitter/innovators-patent-agreement or the most recent "Open Patent Non-Assertion Pledge" published by Google and available at http://www.google.com/patents/opnpledge/pledge/. These different approaches to defensive patent licensing are each tailored to a specific situation or goal, but can serve as a starting point for research and discussion about the purpose and scope patent licenses to be included in standardized contributor agreements.

9 Another interesting drafting option, which is not included in the analysis provided in this dedicated section, is the idea of joint ownership as required by the Oracle Contributor Agreements available at http://www.oracle.com/technetwork/oca-405177.pdf
} 
the project, it may have the side-effect of being perceived as an unfair distribution of power. ${ }^{10}$

In order to properly assess the various arguments for and against copyright assignments as one potential drafting option for contributor agreements, Tim Engelhardt explores a variety of legal consequences in different jurisdictions. Since copyright law in some jurisdictions may not allow for an assignment of copyright but only for a license ${ }^{11}$, one major focus in Tim Engelhardt's analysis is to identify reasons that make an assignment necessary. In other words, if contributor assignment agreements are criticised by some as being unbalanced and may not even be legally effective in some jurisdictions, then what exactly are the legal arguments in favour of assignments? And what can exclusive and non-exclusive licenses offer as alternatives in this context?

Free and open source license agreements usually grant a world wide, exclusive or non-exclusive, perpetual and irrevocable license from the contributor to the project, which includes all of the exclusive rights, such as reproduction, distribution, modification, display, performance and others to allow for the broadest usage of the contribution possible under applicable law. The key question is whether such licenses can represent a satisfying structure of rights between contributors and projects? Depending on projects' values and strategies, the following scenarios will play a major role when choosing between an assignment agreement and a license agreement: 1) ability to make the contribution available under specific outbound licensing models, 2) enforcement in case of legal disputes, 3) bankruptcy and related insolvency proceedings, and 4) death and questions of succession. At least for the two most important issues, sublicensing to multiple peers and enforcement of copyright, Tim Engelhardt suggests that licensing models can achieve the same results as assignments, though only exclusive licensing options enjoy sufficient legal certainty in the US and German context. ${ }^{12}$

\footnotetext{
${ }^{10}$ In situations, where assignments are not desirable, or in jurisdictions, in which assignments are not permissible, another path for further research should be investigated: The question whether the copyright license agreement can provide for additional language and an obligation for the licensor to "assist the project owner in case of enforcement proceedings". This way, the licensee could make a contractual claim on the licensor (contributor) to assign the copyright in case of infringement and related enforcement procedures at any later stage of the project and whenever needed but would not have to be assigned all copyrights right from the start.

${ }^{11}$ This is especially true for copyright law in the Continental European context, in which moral rights play a much bigger role and lead to the argument that the copyright owner can never fully assign her copyright because of the unbreakable bound between the creator and his work.

12 T Engelhardt, "Drafting Options for Contributor Agreements for Free and Open Source Software: Assignment, (Non) Exclusive licence and legal consequences. A Comparative Analysis of German and US law"(2013) 10(2) SCRIPTed, infra, who notes that legal practice in Germany and US suggests for nonexclusive licensing models to enjoy the same results as assignments, but there is some degree of uncertainty as to their ability to be sublicensed. However, even if an exclusive license agreement seems to be the preferable option compared to an assignment agreement, there may still be situations in which an assignment of copyright is desirable. In this case, and to correspond to different national legal requirements, contributor assignment agreements should include a fall-back license as an alternative method to ensure that in jurisdictions prohibiting assignments sufficient rights are granted to projects to permit them to use and distribute the contribution in the same way as the contributor license would permit.
} 
This basic example of different drafting options demonstrates the complexity of the legal and policy questions around contributor agreements. On the one hand side, they can serve as a tool to structure copyright in contributions, on the other hand they have to appropriately balance the interests between different stakeholders. The inherent dichotomy can also raise arguments against the general attempt of standardization. Even if a growing number of projects and established companies are adopting contributor agreements and consequently some common terms are already copied between projects ${ }^{13}$, there are also concerns about the overall need for standardization of contributor agreements based on the argument that no single set of terms can serve all projects and meet their specific values and ideals. While these obstacles to one common language for contributor agreements are important, it is also unquestionable that standard terms would reduce the costs of reviewing and negotiating contributor agreements, which can be especially valuable for developers when they are involved in different projects. And as more projects and companies are adopting contributor agreements, the benefits of standard terms become even more apparent: Widely understood and approved terms would ease the process of explaining, reviewing and negotiating terms between contributors and projects - and across different jurisdictions. $^{14}$

Consequently, the ability for standard terms to be used across multiple jurisdictions is one of the most important aspects for public licenses and contributor agreements. Only a scheme that is legally enforceable in jurisdictions around the world will reduce the overheads involved in scrutinizing different agreements reflecting different legal systems. ${ }^{15}$ One possible solution to address this problem could be further internationalization following the "porting approach", which has been successfully demonstrated by the Creative Commons International project. ${ }^{16}$ Another possibility to address international consequences could be to implement a language, which reflects international standards (e.g. utilize the language of international intellectual property treaties, such as the Berne Convention, the WIPO Copyright Treaty and others). This way, one international agreement would serve various jurisdictions around the world following the GPL or FDL approach and avoiding questions of interoperability of

\footnotetext{
${ }^{13}$ Even though there are various contributor agreements used by various different projects in the free and open source software context, most of the agreements currently available are somewhat based on the concepts and language provided by the Apache Software Foundation contributor license agreement: http://www .apache.org/licenses/icla.txt

${ }^{14}$ The Harmony project tried to seek for a compromise between the two main arguments - the need for standardization to increase efficiency and reduce transaction costs on the one hand side and the need for customized contributor agreements to reflect each project's governance structures and specific values on the other side. The project offered a system, which allowed each user to choose from a set of pre-defined agreements using a standardized language, and which could then be tailored to reflect specific needs, see details at http://harmonyagreements.org

15 To achieve this goal, the licenses and agreements have to respond to the differences and particularities in understanding copyright according to national legislations around the world. Standard copyright terms such as "derivative work" or "distribution" and related interpretation as well as licensing practices differ among jurisdictions and reveal several legal issues. Concepts like moral rights, duration of copyright, transfer of copyright, or even authorship itself (e.g. in case of employment) vary from jurisdiction to jurisdiction and require careful consideration when drafting license agreements or assignments agreements.

16 http://wiki.creativecommons.org/CC_Affiliate_Network and overview at C Maracke, Creative Commons International - The International License Porting Project, jipitec, Vol. 12010.
} 
jurisdictional licenses. When balancing arguments for both solutions, various questions on private international law have to be considered and discussed. The key question to be investigated arises when contributor A, a resident of France, contributes to project $\mathrm{P}$, hosted and organized in the US and using a contributor assignment agreement to structure his rights. In case of infringement, which court would be competent to hear the claim and - more importantly- which law would be applicable? And finally, how can the ruling be enforced elsewhere?

A choice of law clause as used in most agreements is primarily effective only in respect of contractual issues as elucidated by Axel Metzger. ${ }^{17}$ For copyright questions, such as the existence or duration of copyright in a specific instance, the rule of territoriality will have to be applied. ${ }^{18}$ Even if there are different views on how exactly the rule of territoriality has to be understood, there is a tendency that at least for copyright questions dealing with authorship, duration of copyright, moral rights, fair use and/or limitations and exceptions of exclusive copyrights the rule of territoriality will overrule the choice of law clause. ${ }^{19}$ Consequently, all copyright questions are likely governed by the respective national copyright law of the jurisdiction in which protection is being sought. Instead of one global copyright, a bundle of many different national copyrights have to be contemplated. Such a fragmented structure of the global copyright system can raise a variety of issues when it comes to the idea of "porting" public licenses or standardized contributor agreements to various different jurisdictions. While porting allows for enforceability in local courts, this can only be true when a potential national version of the agreements is matched with the respective national copyright law. In other words, a localized version of the agreements will only help in the case of enforcement if there is a mechanism to assure that the corresponding local copyright law will be applicable. And according to the rule of territoriality, this is exactly the missing point in the structure of localized agreements, as the choice of law clause can only define the governing law for contractual questions.

However, when shaping an internationalization strategy for contributor agreements, Axel Metzger points us to the difference between standardization efforts for contributor agreements and standardization efforts for public "outbound" licenses. ${ }^{20}$ Contributor agreements regulate the internal relationship between projects (entities) and programmers or authors, whereas public licenses (such as Creative Commons or he GNU GPL) regulate the external relationship between rightholders and users of the respective program or content. In the first case, programmers and authors (licensors) can be located in multiple different jurisdictions, but the receiving project or entity (licensee) is usually located in a single jurisdiction. In the second case, the contributors to a project or other rightholders, i.e. the licensors, may be spread in different jurisdictions and have to deal with a variety of possible users (licensees)

\footnotetext{
17 See A Metzger,Internationalisation of FOSS Contributory Copyright Assignments and Licences: Jurisdiction-specific of "Unported"? (2013) 10(2) SCRIPTed, who notes that contributor agreements are drafted as transfer or license contracts.

${ }^{18}$ For details see A Metzger infra, who highlights different subcategories of questions, which are governed by different conflict rules.

${ }^{19}$ For infringement and remedies, Art. 8 Rome II Convention provides for a conflict rule.

${ }^{20}$ See A Metzger infra.
} 
most likely located in a number of different jurisdictions. ${ }^{21}$ This important difference between inbound and outbound licensing models has significant implications when it comes to questions on private international law and especially to the impact of a possible choice-of-law clause: Implementing a choice-of-law-clause, even if only relevant for contractual issues, can provide a high level of legal certainty for inbound licensing models, where one project or entity can be identified as licensee. Where the recipient of specific rights (licensee) is located in one specific jurisdiction, choosing that jurisdiction as applicable law will help adding clarity for contractual issues while at the same time will most likely coincide with the applicable law for copyright issues. From the programmers and authors (licensor) point of view, out of the bundle of different copyrights he will most likely have to rely on the law of the jurisdiction where the receiving project is located because that is the location where the potential infringement would most likely take place. Hence, Axel Metzger suggests contributor agreements provide a choice-of-law clause, which chooses the law of the central administration of the project organization or entity and which is drafted in a flexible and open style to allow the court to apply it for all questions which can possibly be determined by such a clause.

Finally, another important aspect of standardization of contributor agreements is analysed by Andres Guadamuz and Andrew Rens: What kind of formalities are required, if any, for copyright assignment and copyright license agreements? While most jurisdictions require or favour recording contributor agreements in text, some jurisdictions require even more than that, insisting on formalities of signature and writing. Any form of standardization of contributor agreements will have to address the question of how to assure legal validity and enforceability in local courts while relieving developers and projects from the burden of additional paper work. As a starting point Andres Guadamuz and Andrew Rens conducted a high level survey and worked with a network of legal experts from various jurisdictions to collect relevant information regarding formalities in copyright transfers and licenses. ${ }^{22}$ The resulting evaluation includes details on formalities for different drafting options and related consequences, such as whether signature formalities are constitutive or probative, that is whether any failure to comply with formalities will completely invalidate the transaction or whether it simply creates problems of evidence. While most jurisdictions require formalities for assignments and exclusive licenses, a technical signature is sufficient in most cases. ${ }^{23}$ Consequently, a simple click-through mechanism that assures each contributor can be identified seems a long overdue simplification for standardized contributor agreements. However, there are jurisdictions in which paper based signature may still be required, especially for contributor assignment agreements.

\footnotetext{
${ }^{21}$ See A Metzger infra.

22 See A Guadamuz and A Rens, Comparative Analysis of Copyright Assignment and Licence Formalities for Open Source Contributor Agreements, (2013) 10(2) SCRIPTed, who have worked with partners around the world and across continents and have received answers from 16 different jurisdictions.

${ }^{23}$ A Guadamuz and A Rens infra, who found that most jurisdictions, accept technical signatures with the exception of Portugal and South Africa, which theoretically accepts technical signatures but only from accredited providers.
} 
In summary, we see the current debate around contributor agreements and different drafting options as an opportunity to further develop best practices for legal strategies to reduce friction involved in moving rights between developers and free and open source software projects. We trust that readers will extend the debate and that this special section will serve as a constructive step forward in the effort to provide clarity and improved guidelines for the next generation of standardized contributor agreements. 